\title{
Qualidade microbiológica do ambiente, alimentos e água, em restaurantes da Ilha do $\mathrm{Mel} / \mathrm{PR}$
}

\section{Microbiological quality ambience, foods and water, in restaurants of Ilha do Mel, Paraná State}

\author{
Ana Paula Pavão Battaglini ${ }^{1 *}$; Rafael Fagnani ${ }^{1}$; Ronaldo Tamanini ${ }^{1}$; Vanerli Beloti ${ }^{2}$
}

\section{Resumo}

Vários surtos de Doenças Transmitidas por Alimentos são notificadas por ano no estado do Paraná, sendo as bactérias responsáveis por $70 \%$ destes surtos e $95 \%$ dos casos de toxinfecções alimentares. Existem relatos de que utensílios e equipamentos contaminados participam de, aproximadamente, $16 \%$ dos surtos. O objetivo deste trabalho foi avaliar a qualidade microbiológica da água, dos alimentos in natura, congelados e expostos ao consumo e as condições higiênico-sanitárias de três restaurantes da Ilha do Mel/PR. Para produtos de origem animal, foi determinada a contagem de aeróbios mesófilos, coliformes totais, E. coli e $S$. aureus. Para equipamentos e utensílios inclui-se, ainda, a contagem de bolores e leveduras. Das superfícies analisadas, 72,2\% apresentaram condições higiênico-sanitárias insatisfatórias. Tábuas plásticas de corte, esponjas de louça, pias e os panos de prato e de pia apresentaram as maiores médias de contaminação. De acordo com a legislação brasileira, os alimentos encontrados em desacordo com os padrões estabelecidos foram: o mexilhão congelado, com contagens de E. coli de 7,0 x $10^{2} \mathrm{UFC} / \mathrm{g}$; o molho de camarão, com $1,4 \times 10^{4} \mathrm{UFC} / \mathrm{g}$; as amostras de alface e cenoura ralada, consideradas limpas, com $1,0 \times 10^{3}$ e $2,0 \times 10^{5} \mathrm{UFC} / \mathrm{g}$ de EC, respectivamente. Os alimentos, de um modo geral, apresentaram altas contagens bacterianas. As verduras e os legumes foram os principais responsáveis pela contaminação de tábuas e pias. A água utilizada nos três restaurantes apresentou qualidade microbiológica satisfatória. $\mathrm{O}$ estabelecimento que apresentou melhores condições higiênico-sanitárias foi o estabelecimento onde os manipuladores foram treinados com cursos de boas práticas de manipulação.

Palavras-chave: Contaminação, cozinhas, manipulação

\begin{abstract}
Each year, several outbreaks of foodborne diseases are reported in Parana state, Brazil. Bacteria are responsible for $70 \%$ of these outbreaks and $95 \%$ of cases of food poisoning. There are reports that kitchen equipment and utensils contaminated have participated of approximately $16 \%$ of outbreaks. The aim of this study was to evaluate the microbiological quality of water, fresh foods, frozen foods, ready to eat food and sanitary conditions of three restaurants in Ilha do Mel - Paraná, Brazil, using Petrifilm ${ }^{\mathrm{TM}}$. The results showed that $72.2 \%$ surfaces of had unsatisfactory sanitary conditions. Cutting boards, scrub sponge, kitchen sinks and dish towels had the highest average contamination. According to Brazilian law, samples of food outside of the standard were: seafood sauce, with 7,0 x $10^{2} \mathrm{CFU} / \mathrm{g}$ of $E$. Coli, frozen mussels, with 7,0 x $10^{2} \mathrm{CFU} / \mathrm{g}$ of E. coli; sample lettuce and grated carrot, considered clean, with 1,0 $\times 10^{3}$ e $2,0 \times 10^{5} \mathrm{CFU} / \mathrm{g}$ of EC, respectively. All samples of food, in general, had high bacterial counts. Vegetables were the main responsible for the contamination of kitchen boards and sinks. The water used in the three restaurants had satisfactory microbiological quality. Better hygienic sanitary conditions were found in the restaurant where the employees had training in good manufacturing practices.
\end{abstract}

Key words: Contamination, kitchens, manipulation

\footnotetext{
1 Discentes da Universidade Estadual de Londrina, UEL, Londrina, PR. E-mail: anapaulabattaglini@gmail.com; rafaelfagnani@ hotmail.com; ronaldot@hotmail.com

2 Prof $^{\mathrm{a}}$ do Dept ${ }^{\mathrm{o}}$ de Medicina Veterinária Preventiva, CCA, UEL, Londrina, PR. E-mail: neli@sercomtel.com.br Autor para correspondência
} 


\section{Introdução}

De acordo com o Center For Disease Control nos EUA, as bactérias são responsáveis pela ocorrência de $70 \%$ dos surtos e de $95 \%$ dos casos de toxinfecções alimentares (ANDRADE; SILVA; BRABES, 2003). Existem relatos de que utensílios e equipamentos contaminados participam de, aproximadamente, $16 \%$ dos surtos. No Brasil, no período de 1999 a 2007, foram notificados 5.699 surtos, envolvendo 114.302 pessoas doentes e 61 óbitos. No Paraná, no ano de 2000, notificaram-se 219 surtos de Doenças Transmitidas por Alimentos (DTA) envolvendo 8.663 doentes e 1.000 hospitalizações (BRASIL, 2007).

Com a impossibilidade de monitorar de forma eficiente a contaminação dos utensílios e alimentos por todos os micro-organismos, utilizase a pesquisa dos micro-organismos denominados indicadores (JAY, 2000). Para produtos de origem animal, a segurança e a qualidade podem ser estimadas com o uso da contagem de aeróbios mesófilos, de coliformes totais e de Escherichia coli e Staphylococcus aureus. Para equipamentos e utensílios inclui-se, ainda, a contagem de bolores e leveduras, que têm sido usados como indicadores da qualidade da sanificação em plantas de processamento de alimentos (FRANCO, 2003).

A Ilha do Mel está localizada no litoral paranaense e é o principal destino turístico do Estado. A estrutura precária dos restaurantes, a impossibilidade de construir instalações melhores, já que se trata de uma reserva ambiental, e a carência de conhecimentos dos manipuladores sobre higiene e conservação de alimentos nas condições dadas podem acarretar riscos à saúde dos consumidores que são, em sua maioria, turistas.

O objetivo deste trabalho foi avaliar a qualidade microbiológica da água, dos alimentos in natura e congelados e prontos ao consumo, e as condições higiênico-sanitárias de três restaurantes da Ilha do Mel/PR. Ainda, pretendeu-se identificar os principais pontos de contaminação, visando a futura implantação de boas práticas nos estabelecimentos, para conferir maior segurança microbiológica aos alimentos oferecidos ao consumo.

\section{Material e Métodos}

Avaliação de conformidades e não conformidades

Foram acompanhadas as atividades de 20 restaurantes, desde antes do início do preparo dos alimentos até, em média, 2 horas após o almoço. Destes 20 restaurantes foram selecionados três com características diferentes de instalações, equipamentos e hábitos de higiene.

Para avaliação das conformidades (C) e não conformidades (NC) foi realizado um check-list, baseado na RDC n⿳275 (BRASIL, 2002), que se aplicasse às condições dos restaurantes.

O check-list foi separado em 3 categorias: manipuladores, instalações e utensílios e cuidados com os alimentos.

\section{Determinação dos principais pontos de contaminação}

Para realização das análises, foi montado um laboratório na sede da ONG AMARÉ, localizada na praia de Encantadas, com os equipamentos do Laboratório de Inspeção de Produtos de Origem Animal (LIPOA) da Universidade Estadual de Londrina. O material, reagentes e diluentes foram previamente preparados, distribuídos e esterilizados no LIPOA para garantir a segurança microbiológica dos procedimentos.

Foram avaliadas diversas superfícies de instalações, equipamentos e utensílios que entraram em contato com o alimento e as mãos dos manipuladores de três restaurantes da Ilha do Mel, antes do início do preparo dos alimentos e durante o processamento. Foram determinadas as contagens de micro-organismos aeróbios mesófilos (AM), coliformes totais (CT), Escherichia coli (EC), Staphylococcus aureus (SA) e bolores e leveduras (BL). 
Para a colheita das amostras foi utilizada a técnica de esfregaço de superfície (ABNT, 1988) utilizando Quick Swabs 3M, contendo $1 \mathrm{~mL}$ de caldo Letheen e moldes plásticos estéreis.

Os pontos demarcados variaram de 1 a $3(15,50$ ou $150 \mathrm{~cm}^{2}$ ), dependendo da área do equipamento ou instalação (ABNT, 1988). Quando utilizado mais de um $s w a b$ por ponto amostrado foi realizado um pool do conteúdo de todos swabs. Para a casquinha do siri e a abertura da caixa de leite UHT foi amostrada toda a área interna.

As amostras foram submetidas à diluições decimais seriadas em solução salina peptonada $(0,1 \%)$ estéril.

Utilizou-se Petrifilm ${ }^{\mathrm{TM}}$ AC, EC, STX e YM, para enumeração de AM, CT e EC, SA e $\mathrm{BL}$, respectivamente, conforme orientações do fabricante (3M Company, St. Paul, MN, EUA). Para a análise da água, utilizou-se duas diferentes placas de Petrifilm (Petrifilm ${ }^{\mathrm{TM}}$ EC e Petrifilm ${ }^{\mathrm{TM}}$ HS) com o objetivo de detectar a possível presença de coliformes e E. coli (BELOTI et al., 2002).

As contagens obtidas foram corrigidas de acordo com a diluição utilizada e a área ou quantidade de alimento amostrada. Os resultados foram expressos em Unidades Formadoras de Colônia (UFC) $/ \mathrm{cm}^{2}$ ou g ou $\mathrm{mL}$.

\section{Análise microbiológica dos alimentos e da água}

Foram determinadas as contagens de AM, CT, EC e SA para os alimentos e CT e EC para a água.

Foram coletadas 33 amostras de alimentos, in natura e congelados, e do mesmo alimento pronto para servir. Também foram coletadas três amostras da água das torneiras dos estabelecimentos, além da água das três bicas localizadas na praia do Mar de Fora que são utilizadas para o preparo dos alimentos e sucos. As amostras foram transportadas refrigeradas em bolsas estéreis até o laboratório. Para as amostras líquidas foi semeado $1 \mathrm{~mL}$ da amostra em 9 mL de solução salina peptonada $(0,1 \%)$ estéril. Para amostras sólidas foram homogeneizados $5 \mathrm{~g}$ do alimento em $45 \mathrm{~mL}$ de água peptonada $(0,1 \%)$ estéril, em Stomacher (ITR, Brasil) por 3 minutos; após foram realizadas diluições decimais seriadas em solução salina peptonada $(0,1 \%)$ estéril.

\section{Resultados e Discussão}

A Tabela 1 demonstra as médias obtidas nas contagens de AM, CT, EC, SA e BL das superfícies das instalações, equipamentos, utensílios e mãos dos manipuladores. As Tabelas 2, 3 e 4 mostram as contagens de AM, CT, EC, SA e BL das superfícies das instalações, equipamentos, utensílios e mãos dos manipuladores dos restaurantes R1, R2 e R3, respectivamente.

Se considerarmos a recomendação da American Public Health Association (APHA), de que a contagem de AM não ultrapasse 2 UFC/ $\mathrm{cm}^{2}$ (SVEUM et al., 1992), nenhuma superfície estudada estaria em condições higiênico-sanitárias satisfatórias. Entretanto, a recomendação americana é considerada muito rígida para restaurantes brasileiros. Outros autores (GILL, 1998; EISEL; LINTON; MURIANA, 1997) consideram que superfícies visivelmente limpas podem apresentar contagens totais de 10 a $10^{3} \mathrm{UFC} / \mathrm{cm}^{2}$ de AM. No presente estudo, das 18 superfícies testadas, 13 (72,2\%) apresentaram contagens médias de AM superiores a $10^{3} \mathrm{UFC} / \mathrm{cm}^{2}$. A abertura da caixa de leite UHT $\left(>3,0 \times 10^{8}\right)$, a casquinha do siri $(>3,0$ x $\left.10^{8}\right)$, as tábuas de corte $\left(3,2 \times 10^{6} \mathrm{UFC} / \mathrm{cm}^{2}\right)$, as esponjas de louça $\left(5,0 \times 10^{6} \mathrm{UFC} / \mathrm{cm}^{2}\right)$, as pias $\left(1,3 \times 10^{4} \mathrm{UFC} / \mathrm{cm}^{2}\right)$ e os panos de prato $(2,8 \mathrm{x}$ $10^{4} \mathrm{UFC} / \mathrm{cm}^{2}$ ) apresentaram as maiores médias de contaminação por AM. Coelho et al. (2010) encontraram contagens de AM de até $7,8 \times 10^{5} \mathrm{UFC} /$ $\mathrm{cm}^{2}$ em superfícies, 1,9 x $10^{8}$ em utensílios e 18,3 x $10^{7}$ em equipamentos de cozinhas de restaurantes self-service, e consideraram que as condições de higiene dos restaurantes eram precárias. Kochanski et al. (2009), encontraram as maiores contagens 
de AM nas bancadas e as menores nas tábuas de corte, diferente do encontrado neste trabalho. Diferentes resultados podem ser explicados pelo tipo de alimento produzido, pelos hábitos de higiene dos manipuladores e pelas instalações dos estabelecimentos.

As maiores contagem de CT foram obtidas da abertura da caixa do leite UHT (1,3 x $10^{7}$ UFC), da esponja de louça $\left(5,0 \times 10^{5} \mathrm{UFC} / \mathrm{cm}^{2}\right)$, da casquinha do siri (1,0 x $10^{4} \mathrm{UFC} /$ superfície) e das tábuas de corte durante o trabalho $\left(2,0 \times 10^{4} \mathrm{UFC} / \mathrm{cm}^{2}\right)$. Foi observada a presença de EC em $10(16,2 \%)$ das 60 superfícies analisadas, o que indica contaminação de origem fecal. Algumas superfícies já se encontravam contaminadas no início do trabalho, outras se contaminaram durante o trabalho, provavelmente pelo contato com verduras, legumes e alimentos crus contaminados. Estudando cozinhas da fronteira mexicana, Carrasco et al. (2008) encontraram contaminação por EC em $40 \%$ das pias, $28 \%$ das bancadas, $19 \%$ das tábuas de corte, $14 \%$ das mãos dos manipuladores e $9 \%$ dos refrigeradores. No presente estudo, foi encontrada a presença de EC em $37,5 \%$ das bancadas, $27,3 \%$ dos freezers, $20 \%$ das pias e $20 \%$ das tábuas de corte.

A presença de micro-organismos em superfícies de cozinhas, além de causar deterioração do alimento, aumenta o risco de toxinfecções de origem alimentar. A presença de E. coli, por exemplo, indica que enterobactérias podem estar presentes, como a Salmonella, bactéria responsável por inúmeros casos de surtos de infecção alimentar.

Todas as instalações e equipamentos analisadas encontravam-se contaminadas por bolores e leveduras. As tábuas plásticas de corte iniciaram os trabalhos limpas, mas foram se contaminando durante o trabalho, devido a contaminação cruzada. Tábuas de corte e panos de pia foram os pontos que apresentaram maiores médias de contagens de leveduras: $2,1 \times 10^{4}$ e $1,5 \times 10^{4} \mathrm{UFC} / \mathrm{cm}^{2}$, respectivamente, demonstrando que não vêm sendo bem higienizados ao longo do tempo, uma vez que estes micro-organismos levam de 5 a 7 dias para crescer. A maior contagem de bolores foi encontrada na casquinha do siri $\left(2,7 \times 10^{4} \mathrm{UFC} /\right.$ superfície $)$.

Algumas superfícies e utensílios de cozinha favorecem a adesão, multiplicação e a sobrevivência de micro-organismos devido à composição do material e ao seu uso constante sem a higienização e substituição adequadas. É o caso da esponja de louça, que retém restos de alimentos e umidade, sendo um importante veículo transmissor de microorganismos, incluindo os patogênicos. Neste estudo, das três esponjas analisadas, duas apresentaram altíssimas contagens de AM $\left(8,7 \times 10^{4}\right.$ e $1,5 \times$ $\left.10^{8} \mathrm{UFC} / \mathrm{cm}^{2}\right)$ e CT $\left(1,3 \times 10^{4}\right.$ e $5,0 \times 10^{5} \mathrm{UFC} /$ $\mathrm{cm}^{2}$ ), representando um dos principais pontos de contaminação dentro da cozinha. Diversos autores relataram a presença de altas contagens de microorganismos nas esponjas de louça (JOSEPHSON; RUBINO; PEPPER, 1997; RUSIN; OROSZCOUGHLIN; GERBA, 1998).

As tábuas plásticas de corte e as pias também apresentaram altas contagens de micro-organismos AM, CT, EC e BL, sendo consideradas importantes fontes de contaminação. $O$ contato com os alimentos, verduras e legumes crus pode ter sido o principal motivo de contaminação das tábuas de corte e das pias, principalmente por bactérias do grupo coliformes. Coelho et al. (2010) também encontraram contagens de AM de até $1,9 \times 10^{8}$ $\mathrm{UFC} / \mathrm{cm}^{2}$.

O uso de panos de limpeza (pano de prato e pano de pia), embora não recomendado, é uma prática comum na maioria dos restaurantes. Esses panos são amplamente utilizados nos procedimentos de limpeza de instalações, equipamentos e utensílios e, por esse motivo, podem facilmente acumular e disseminar resíduos de alimentos e microorganismos por toda a cozinha. No presente estudo, foram encontradas médias de AM de 2,8 x $10^{4}$ $\mathrm{UFC} / \mathrm{cm}^{2}$, nos panos de prato, e $2,2 \times 10^{3} \mathrm{UFC} /$ $\mathrm{cm}^{2}$, nos panos de pia e altas contagens de CT nos panos de prato e de pia $\left(1,3 \times 10^{3}\right.$ e $2,9 \times 10^{2} \mathrm{UFC} /$ $\mathrm{cm}^{2}$, respectivamente), além da presença de $\mathrm{SA}$ em uma amostra de pano de prato. Neste estudo, 
a amostragem dos panos de limpeza foi realizada somente da superfície, assim, a contaminação real provavelmente seja muito maior. A quantidade de micro-organismos presentes nos panos de limpeza frequentemente é bastante alta, conforme relatado por diversos autores (JOSEPHSON; RUBINO; PEPPER, 1997; COGAN; BLOOMFIELD; HUMPHREY, 1999).

Geladeiras e freezers também são frequentemente relacionados ao risco de contaminação cruzada, incluindo a contaminação de alimentos prontos (JACKSON et al., 2007). Neste estudo, as geladeiras não foram consideradas importantes fontes de contaminação. Entretanto, em 50\% das amostras de gelo dos freezers havia a presença de $E$. coli. Falcão et al. (2002) encontraram resultados semelhantes aos deste trabalho e consideraram a qualidade do gelo insatisfatória.
Manipuladores de alimentos são um dos principais transmissores de micro-organismos durante o processamento dos alimentos. Analisando as mãos de seis manipuladores, foi encontrada a presença de CT em cinco, antes e durante o trabalho. A presença de SA foi encontrada em dois $(35 \%)$ dos seis manipuladores, ambas as amostras foram colhidas durante o trabalho. Andrade, Silva e Brabes (2003), estabeleceram uma classificação de higiene para manipuladores de acordo com a contagem de AM nos seguintes intervalos: até $100 \mathrm{UCF} / \mathrm{cm}^{2}$ (bom); entre 101 e $1.000 \mathrm{UFC} / \mathrm{cm}^{2}$ (regular); entre 1.001 e $10.000 \mathrm{UFC} / \mathrm{cm}^{2}$ (ruim). Considerando o resultado apresentado na Tabela 4, a higiene dos manipuladores foi considerada regular. Se considerarmos as análises individuais, cinco manipuladores teriam classificação de higiene ruim.

Tabela 1. Média das contagens de aeróbios mesófilos (AM), coliformes totais (CT), E. coli (EC), S. aureus (SA), bolores e leveduras das superfícies das instalações, equipamentos, utensílios e mãos dos manipuladores de três restaurantes da Ilha do Mel/PR (UFC/ $\mathrm{cm}^{2}$ ), em janeiro de 2010.

\begin{tabular}{lccccccc}
\hline \multicolumn{1}{c}{$\begin{array}{c}\text { Descrição das } \\
\text { amostras }\end{array}$} & $\mathbf{n}$ & $\mathbf{A M}$ & $\mathbf{C T}$ & $\mathbf{E C}$ & $\mathbf{S A}$ & Bolores & Leveduras \\
\hline bancada início & 3 & $8,4 \times 10^{2}$ & $2,4 \times 10^{2}$ & 0,9 & $\mathrm{NR}$ & $3,6 \times 10^{1}$ & $1,9 \times 10^{1}$ \\
bancada durante & 3 & $8,7 \times 10^{2}$ & $1,5 \times 10^{2}$ & 0,1 & $\mathrm{NR}$ & 2,2 & $2,3 \times 10^{2}$ \\
pia início & 5 & $1,3 \times 10^{4}$ & $4,2 \times 10^{2}$ & $3,0 \times 10^{1}$ & $\mathrm{NR}$ & $2,5 \times 10^{1}$ & $2,8 \times 10^{1}$ \\
pia durante & 5 & $3,8 \times 10^{3}$ & $1,0 \times 10^{2}$ & $<0,1$ & $\mathrm{NR}$ & $1,3 \times 10^{1}$ & $2,0 \times 10^{2}$ \\
geladeira & 5 & $1,8 \times 10^{2}$ & $8,5 \times 10^{1}$ & $<0,3$ & $\mathrm{NR}$ & $1,7 \times 10^{1}$ & $1,2 \times 10^{2}$ \\
gelo do freezer & 6 & $4,3 \times 10^{3}$ & $1,0 \times 10^{2}$ & 0,8 & $\mathrm{NR}$ & $7,1 \times 10^{1}$ & $6,8 \times 10^{2}$ \\
fatiador & 1 & $3,3 \times 10^{1}$ & $<0,3$ & $<0,3$ & $\mathrm{NR}$ & $1,3 \times 10^{2}$ & $1,3 \times 10^{2}$ \\
tábua início & 5 & $3,1 \times 10^{2}$ & 7,6 & $<0,3$ & $\mathrm{NR}$ & $8,5 \times 10^{1}$ & $2,7 \times 10^{2}$ \\
tábua durante & 5 & $3,2 \times 10^{6}$ & $6,6 \times 10^{3}$ & 0,9 & $\mathrm{NR}$ & $5,4 \times 10^{2}$ & $2,0 \times 10^{4}$ \\
faca início & 3 & $1,6 \times 10^{1}$ & 7,1 & $<0,7$ & $\mathrm{NR}$ & $\mathrm{NR}$ & $\mathrm{NR}$ \\
faca durante & 3 & $4,5 \times 10^{3}$ & $2,3 \times 10^{1}$ & $<0,7$ & $\mathrm{NR}$ & $\mathrm{NR}$ & $\mathrm{NR}$ \\
esponja de louça & 3 & $5,0 \times 10^{6}$ & $1,7 \times 10^{5}$ & $<0,3$ & $\mathrm{NR}$ & 4,0 & $1,4 \times 10^{2}$ \\
pano de prato & 3 & $2,8 \times 10^{4}$ & $1,3 \times 10^{3}$ & $<0,3$ & 1,1 & 0,9 & 7,1 \\
pano de pia & 2 & $2,2 \times 10^{3}$ & $2,9 \times 10^{2}$ & $<0,3$ & $<0,3$ & $3,4 \times 10^{1}$ & $1,5 \times 10^{4}$ \\
travessa início & 3 & $4,5 \times 10^{2}$ & $<0,3$ & $<0,3$ & $\mathrm{NR}$ & $\mathrm{NR}$ & $\mathrm{NR}$ \\
travessa durante & 3 & $4,2 \times 10^{3}$ & 3,3 & $<0,3$ & $\mathrm{NR}$ & $\mathrm{NR}$ & $\mathrm{NR}$ \\
casquinha do siri* & 1 & $>3,0 \times 10^{8}$ & $1,0 \times 10^{4}$ & $<10$ & $\mathrm{NR}$ & $2,7 \times 10^{4}$ & $<3,0 \times 10^{2}$ \\
abertura caixa leite* & 1 & $>3,0 \times 10^{8}$ & $1,3 \times 10^{7}$ & $<10$ & $\mathrm{NR}$ & $\mathrm{NR}$ & $\mathrm{NR}$ \\
mão início & 6 & $1,1 \times 10^{3}$ & $4,1 \times 10^{1}$ & $<0,7$ & $<0,7$ & $\mathrm{NR}$ & $\mathrm{NR}$ \\
mão durante & 6 & $7,3 \times 10^{2}$ & $7,2 \times 10^{1}$ & $<0,7$ & $3,5 \times 10^{1}$ & $\mathrm{NR}$ & $\mathrm{NR}$ \\
\hline \multicolumn{1}{c}{ Total } & $\mathbf{7 2}$ & & & & & & \\
\hline
\end{tabular}

n: número de amostras $\quad$ NR: não realizado $\quad$ *UFC/superfície

Fonte: Elaboração dos autores. 
Tabela 2. Contagens de aeróbios mesófilos (AM), coliformes totais (CT), E. coli (EC), S. aureus (SA), bolores e leveduras das superfícies das instalações, equipamentos, utensílios e mãos dos manipuladores do restaurante R1 da Ilha do Mel/PR (UFC/cm²), em janeiro de 2010.

\begin{tabular}{|c|c|c|c|c|c|c|}
\hline Descrição das amostras & AM & CT & EC & $\mathbf{S A}$ & Bolores & Leveduras \\
\hline bancada início & 5,0 & 0,05 & $<0,2$ & NR & 6,5 & 3,0 \\
\hline bancada durante & $2,1 \times 10^{3}$ & $4,0 \times 10^{2}$ & 0,4 & NR & 4,0 & $5,5 \times 10^{2}$ \\
\hline pia de lavar louça início & $1,9 \times 10^{2}$ & $1,7 \times 10^{2}$ & $<0,2$ & NR & 3,0 & $1,0 \times 10^{1}$ \\
\hline pia de lavar louça durante & $1,5 \times 10^{2}$ & $1,5 \times 10^{1}$ & $<0,2$ & NR & $5,0 \times 10^{1}$ & $1,0 \times 10^{2}$ \\
\hline pia descong. início & $1,4 \times 10^{2}$ & $4,5 \times 10^{1}$ & $<0,2$ & NR & 0,5 & $3,0 \times 10^{1}$ \\
\hline pia descong. durante & $1,7 \times 10^{4}$ & $9,5 \times 10^{1}$ & 0,05 & NR & $1,0 \times 10^{1}$ & $7,5 \times 10^{2}$ \\
\hline geladeira de salada & $<0,3$ & $<0,3$ & $<0,3$ & NR & $6,7 \times 10^{1}$ & $6,7 \times 10^{1}$ \\
\hline $\begin{array}{l}\text { geladeira de molhos, } \\
\text { conservas e marisco }\end{array}$ & $<2,0 \times 10^{2}$ & 2,0 & $<0,3$ & NR & $1,2 \times 10^{1}$ & $3,3 \times 10^{2}$ \\
\hline $\begin{array}{l}\text { geladeira de molhos, } \\
\text { conservas, queijos e } \\
\text { presunto }\end{array}$ & $1,1 \times 10^{2}$ & $<0,3$ & $<0,3$ & NR & 4,0 & $9,8 \times 10^{1}$ \\
\hline esponja de louça & $1,5 \times 10^{8}$ & $5,0 \times 10^{5}$ & $<0,3$ & NR & 2,0 & $4,8 \times 10^{1}$ \\
\hline pano de prato & $6,4 \times 10^{2}$ & $5,3 \times 10^{2}$ & $<0,3$ & $<0,3$ & 1,3 & 8,7 \\
\hline tábua início & $<6,7$ & 0,7 & $<0,3$ & NR & 0,7 & $1,1 \times 10^{3}$ \\
\hline tábua durante & $1,0 \times 10^{4}$ & $2,3 \times 10^{3}$ & $<0,3$ & NR & $3,3 \times 10^{4}$ & $8,0 \times 10^{4}$ \\
\hline fatiador & $3,3 \times 10^{1}$ & $<0,3$ & $<0,3$ & NR & $1,3 \times 10^{2}$ & $1,3 \times 10^{2}$ \\
\hline travessa início & $1,3 \times 10^{3}$ & $<0,3$ & $<0,3$ & NR & NR & NR \\
\hline travessa durante & $1,3 \times 10^{4}$ & 8,7 & $<0,3$ & NR & NR & NR \\
\hline faca início & $3,3 \times 10^{1}$ & $2,0 \times 10^{1}$ & $<0,7$ & NR & NR & NR \\
\hline faca durante & $<6,7$ & $<0,7$ & $<0,7$ & NR & NR & NR \\
\hline mão 1 início & $2,3 \times 10^{3}$ & 4,7 & $<0,7$ & $<0,7$ & NR & NR \\
\hline mão 1 durante & $5,7 \times 10^{2}$ & 6,0 & $<0,7$ & $<0,7$ & NR & NR \\
\hline mão 2 início & $2,6 \times 10^{3}$ & $2,2 \times 10^{2}$ & $<0,7$ & $<0,7$ & NR & NR \\
\hline mão 2 durante & $1,7 \times 10^{3}$ & $2,7 \times 10^{2}$ & $<0,7$ & $2,0 \times 10^{2}$ & NR & NR \\
\hline $\begin{array}{l}\text { gelo do freezer de peixes } \\
\text { grandes, filés, camarão } \\
\text { e lula }\end{array}$ & $2,0 \times 10^{2}$ & $5,4 \times 10^{1}$ & 3,0 & NR & $1,0 \times 10^{2}$ & $1,0 \times 10^{3}$ \\
\hline $\begin{array}{l}\text { gelo do freezer de carne } \\
\text { vermelha e frango }\end{array}$ & $1,0 \times 10^{2}$ & 5,0 & $<1,0$ & NR & $<1,0$ & $7,0 \times 10^{2}$ \\
\hline $\begin{array}{l}\text { gelo do freezer de peixes } \\
\text { peq., iscas, camarão e } \\
\text { frutos do mar }\end{array}$ & $1,0 \times 10^{2}$ & $3,7 \times 10^{1}$ & 1,0 & NR & 9,0 & $4,5 \times 10^{1}$ \\
\hline $\begin{array}{l}\text { gelo do freezer de batata } \\
\text { e aipim }\end{array}$ & $1,0 \times 10^{2}$ & $<1,0$ & $<1,0$ & NR & 1,0 & 1,0 \\
\hline casquinha do siri* & $>6,0 \times 10^{7}$ & $2,0 \times 10^{4}$ & $<10$ & NR & $2,7 \times 10^{4}$ & $3,0 \times 10^{5}$ \\
\hline abertura caixa leite UHT* & $>3,0 \times 10^{8}$ & $1,3 \times 10^{7}$ & $<10$ & NR & NR & NR \\
\hline
\end{tabular}

NR: não realizado *UFC/superfície

Fonte: Elaboração dos autores. 
Tabela 3. Contagens de aeróbios mesófilos (AM), coliformes totais (CT), E. coli (EC), S. aureus (SA), bolores e leveduras das superfícies das instalações, equipamentos, utensílios e mãos dos manipuladores do restaurante R2 da Ilha do Mel/PR (UFC/ $\left.\mathrm{cm}^{2}\right)$, em janeiro de 2010.

\begin{tabular}{lcccccc}
\hline Descrição das amostras & $\mathbf{A M}$ & $\mathbf{C T}$ & $\mathbf{E C}$ & SA & Bolores & Leveduras \\
\hline bancada início & $2,4 \times 10^{3}$ & $7,0 \times 10^{2}$ & 2,4 & $\mathrm{NR}$ & 1,5 & $4,9 \times 10^{1}$ \\
bancada durante & $4,3 \times 10^{2}$ & $4,0 \times 10^{1}$ & $<0,2$ & $\mathrm{NR}$ & 0,5 & $1,1 \times 10^{1}$ \\
pia início & $5,8 \times 10^{4}$ & $1,0 \times 10^{3}$ & $1,5 \times 10^{1}$ & $\mathrm{NR}$ & $2,2 \times 10^{1}$ & $7,2 \times 10^{1}$ \\
pia durante & $6,8 \times 10^{2}$ & $7,0 \times 10^{1}$ & $<0,2$ & $\mathrm{NR}$ & $<0,5$ & $1,7 \times 10^{1}$ \\
geladeira & $2,7 \times 10^{2}$ & $4,0 \times 10^{2}$ & $<0,3$ & $\mathrm{NR}$ & 2,7 & $1,7 \times 10^{1}$ \\
esponja de louça & $8,7 \times 10^{4}$ & $1,3 \times 10^{4}$ & $<0,3$ & $\mathrm{NR}$ & 4,0 & $8,9 \times 10^{1}$ \\
pano de prato & $8,2 \times 10^{4}$ & $3,3 \times 10^{3}$ & $<0,3$ & 2,7 & 0,7 & $1,2 \times 10^{1}$ \\
pano de pia & $4,3 \times 10^{3}$ & $5,3 \times 10^{2}$ & $<0,3$ & $<0,3$ & 0,7 & $6,5 \times 10^{1}$ \\
tábua carne início & $7,8 \times 10^{2}$ & $<0,3$ & $<0,3$ & $\mathrm{NR}$ & $4,0 \times 10^{2}$ & $1,3 \times 10^{2}$ \\
tábua carne durante & $1,4 \times 10^{5}$ & $9,1 \times 10^{3}$ & 4,7 & $\mathrm{NR}$ & $2,7 \times 10^{2}$ & $5,8 \times 10^{3}$ \\
tábua verdura início & $1,3 \times 10^{1}$ & 5,3 & $<0,3$ & $\mathrm{NR}$ & 4,0 & $9,0 \times 10^{1}$ \\
tábua verdura durante & $1,6 \times 10^{7}$ & $2,0 \times 10^{4}$ & $<0,3$ & $\mathrm{NR}$ & $6,7 \times 10^{1}$ & $2,3 \times 10^{4}$ \\
travessa início & 6,7 & $<0,3$ & $<0,3$ & $\mathrm{NR}$ & $\mathrm{NR}$ & $\mathrm{NR}$ \\
travessa durante & 6,7 & $<0,3$ & $<0,3$ & $\mathrm{NR}$ & $\mathrm{NR}$ & $\mathrm{NR}$ \\
faca início & $1,0 \times 10^{2}$ & $<0,7$ & $<0,7$ & $\mathrm{NR}$ & $\mathrm{NR}$ & $\mathrm{NR}$ \\
faca durante & $1,3 \times 10^{4}$ & $6,8 \times 10^{1}$ & $<0,7$ & $\mathrm{NR}$ & $\mathrm{NR}$ & $\mathrm{NR}$ \\
mão 1 início & $4,1 \times 10^{2}$ & 4,7 & $<0,7$ & $<0,7$ & $\mathrm{NR}$ & $\mathrm{NR}$ \\
mão 1 durante & $1,5 \times 10^{3}$ & 7,3 & $<0,7$ & $<0,7$ & $\mathrm{NR}$ & $\mathrm{NR}$ \\
mão 2 início & 3,3 & $<0,7$ & $<0,7$ & $<0,7$ & $\mathrm{NR}$ & $\mathrm{NR}$ \\
mão 2 durante & $3,3 \times 10^{1}$ & $<0,7$ & $<0,7$ & 4,7 & $\mathrm{NR}$ & $\mathrm{NR}$ \\
gelo freezer & $2,5 \times 10^{4}$ & $5,0 \times 10^{2}$ & 1,0 & $\mathrm{NR}$ & $3,0 \times 10^{2}$ & $2,3 \times 10^{3}$ \\
\hline
\end{tabular}

NR: não realizado

Fonte: Elaboração dos autores.

Tabela 4. Contagens de aeróbios mesófilos (AM), coliformes totais (CT), E. coli (EC), S. aureus (SA), bolores e leveduras das superfícies das instalações, equipamentos, utensílios e mãos dos manipuladores do restaurante R3 da Ilha do Mel/PR (UFC/ $\left.\mathrm{cm}^{2}\right)$, em janeiro de 2010.

\begin{tabular}{lcccccc}
\hline Descrição das amostras & $\mathbf{A M}$ & $\mathbf{C T}$ & $\mathbf{E C}$ & SA & Bolores & Leveduras \\
\hline bancada início & $8,5 \times 10^{1}$ & 3,6 & 0,2 & $\mathrm{NR}$ & $1,0 \times 10^{2}$ & 6,0 \\
bancada durante & $5,5 \times 10^{1}$ & 0,7 & $<0,2$ & $\mathrm{NR}$ & 2,0 & $1,2 \times 10^{2}$ \\
pia de fora início & $3,5 \times 10^{3}$ & $6,4 \times 10^{2}$ & $<0,2$ & $\mathrm{NR}$ & $1,0 \times 10^{2}$ & $1,4 \times 10^{1}$ \\
pia de fora durante & $4,5 \times 10^{2}$ & $1,7 \times 10^{2}$ & $<0,2$ & $\mathrm{NR}$ & 2,5 & $1,5 \times 10^{1}$ \\
pia de dentro início & $1,2 \times 10^{3}$ & $2,6 \times 10^{2}$ & $<0,2$ & $\mathrm{NR}$ & 0,5 & $1,5 \times 10^{1}$ \\
pia de dentro durante & $7,9 \times 10^{2}$ & $1,6 \times 10^{2}$ & $<0,2$ & $\mathrm{NR}$ & 0,5 & $1,2 \times 10^{2}$ \\
geladeira & $3,3 \times 10^{2}$ & $2,1 \times 10^{1}$ & $<0,3$ & $\mathrm{NR}$ & $<0,3$ & $6,3 \times 10^{1}$ \\
esponja de louça & $8,7 \times 10^{2}$ & $4,0 \times 10^{2}$ & $<0,3$ & $\mathrm{NR}$ & 6,0 & $2,8 \times 10^{2}$ \\
pano de prato & $<6,7$ & $<0,3$ & $<0,3$ & $\mathrm{NR}$ & $<0,3$ & $<0,3$ \\
pano de pia & $1,4 \times 10^{2}$ & $3,9 \times 10^{1}$ & $<0,3$ & $<0,3$ & $6,7 \times 10^{1}$ & $3,1 \times 10^{4}$ \\
tábua carne início & $1,2 \times 10^{2}$ & $3,1 \times 10^{1}$ & $<0,3$ & $\mathrm{NR}$ & $1,1 \times 10^{1}$ & $3,7 \times 10^{1}$ \\
tábua carne durante & $3,0 \times 10^{2}$ & $4,3 \times 10^{1}$ & $<0,3$ & $\mathrm{NR}$ & $4,0 \times 10^{1}$ & $7,1 \times 10^{1}$ \\
tábua verdura início & 0,7 & $<0,3$ & $<0,3$ & $\mathrm{NR}$ & 8,0 & 1,3 \\
tábua verdura durante & $1,1 \times 10^{4}$ & $1,3 \times 10^{3}$ & 0,7 & $\mathrm{NR}$ & $6,7 \times 10^{1}$ & $1,3 \times 10^{2}$ \\
travessa início & $<6,7$ & $<0,3$ & $<0,3$ & $\mathrm{NR}$ & $\mathrm{NR}$ & $\mathrm{NR}$
\end{tabular}


continuação

\begin{tabular}{lcccccc} 
travessa durante & $2,7 \times 10^{1}$ & $<0,3$ & $<0,3$ & $\mathrm{NR}$ & $\mathrm{NR}$ & $\mathrm{NR}$ \\
faca início & $<1,0 \times 10^{1}$ & $1,0 \times 10^{1}$ & $<0,7$ & $\mathrm{NR}$ & $\mathrm{NR}$ & $\mathrm{NR}$ \\
faca durante & $9,0 \times 10^{2}$ & $2,0 \times 10^{1}$ & $<0,7$ & $\mathrm{NR}$ & $\mathrm{NR}$ & $\mathrm{NR}$ \\
mão 1 início & $1,3 \times 10^{3}$ & 6,7 & $<0,7$ & $<0,7$ & $\mathrm{NR}$ & $\mathrm{NR}$ \\
mão 1 durante & $3.1 \times 10^{2}$ & 2,7 & $<0,7$ & $<0,7$ & $\mathrm{NR}$ & $\mathrm{NR}$ \\
mão 2 início & $1,5 \times 10^{2}$ & 9,3 & $<0,7$ & $<0,7$ & $\mathrm{NR}$ & $\mathrm{NR}$ \\
mão 2 durante & $2,3 \times 10^{2}$ & $1,5 \times 10^{2}$ & $<0,7$ & $<0,7$ & $\mathrm{NR}$ & $\mathrm{NR}$ \\
gelo freezer & $2,8 \times 10^{2}$ & 4,0 & $<1,0$ & $\mathrm{NR}$ & $1,8 \times 10^{1}$ & $5,5 \times 10^{1}$ \\
\hline
\end{tabular}

NR: não realizado

Fonte: Elaboração dos autores.

Nas Tabelas 5, 6 e 7 estão as contagens de AM, CT, EC, e SA das amostras de alimentos dos 3 restaurantes analisados (R1, R2 e R3, respectivamente).
Na Tabela 8 estão demonstradas as médias das contagens de AC, CT, EC e SA das 33 amostras de alimentos.

Tabela 5. Contagens de aeróbios mesófilos (AM), coliformes totais (CT), E. coli (EC) e S. aureus (SA) do restaurante R1 da Ilha do Mel/PR, em janeiro de 2010.

\begin{tabular}{lcccc}
\hline \multicolumn{1}{c}{ Alimentos } & AM & CT & EC & SA \\
\hline leite utilizado para cozinhar & $2,5 \times 10^{4}$ & $2,6 \times 10^{2}$ & $<10$ & $\mathrm{NR}$ \\
peixe cru & $2,5 \times 10^{4}$ & $3,0 \times 10^{1}$ & $<10$ & $1,0 \times 10^{1}$ \\
camarão cru & $2,2 \times 10^{7}$ & $1,0 \times 10^{5}$ & $2,0 \times 10^{1}$ & $1,0 \times 10^{1}$ \\
anéis de lula congelados & $4,5 \times 10^{5}$ & $3,3 \times 10^{2}$ & $<10$ & $1,0 \times 10^{1}$ \\
carne de siri pronta & $3,0 \times 10^{8}$ & $1,1 \times 10^{2}$ & $<10$ & $<10$ \\
peixe frito & $1,3 \times 10^{6}$ & $2,6 \times 10^{2}$ & $<10$ & $<10$ \\
camarão frito & $3,3 \times 10^{6}$ & $1,3 \times 10^{2}$ & $<10$ & $1,0 \times 10^{1}$ \\
molho de camarão & $3,0 \times 10^{6}$ & $5,0 \times 10^{4}$ & $1,4 \times 10^{4}$ & $<10$ \\
molho belle munière & $2,4 \times 10^{7}$ & $1,0 \times 10^{4}$ & $<10$ & $1,0 \times 10^{1}$ \\
vinagrete de mexilhão & $4,3 \times 10^{6}$ & $1,0 \times 10^{1}$ & $<10$ & $1,0 \times 10^{1}$ \\
presunto fatiado & $1,2 \times 10^{7}$ & $1,1 \times 10^{7}$ & $<10$ & $1,0 \times 10^{1}$ \\
queijo parmesão & $1,3 \times 10^{8}$ & $5,1 \times 10^{4}$ & $3,0 \times 10^{1}$ & $<10$ \\
queijo mussarela & $\mathrm{NR}$ & $3,7 \times 10^{5}$ & $<10$ & $1,0 \times 10^{1}$ \\
salada & $\mathrm{NR}$ & $1,2 \times 10^{7}$ & $<10$ & $\mathrm{NR}$ \\
alface & $\mathrm{NR}$ & $1,0 \times 10^{6}$ & $1,0 \times 10^{3}$ & $\mathrm{NR}$ \\
pepino & $\mathrm{NR}$ & $1,4 \times 10^{7}$ & $<10$ & $\mathrm{NR}$ \\
cenoura ralada & $\mathrm{NR}$ & $6,4 \times 10^{7}$ & $2,0 \times 10^{5}$ & $\mathrm{NR}$ \\
\hline
\end{tabular}

NR: não realizado

Fonte: Elaboração dos autores. 
Tabela 6. Contagens de aeróbios mesófilos (AM), coliformes totais (CT), E. coli (EC) e $S$. aureus (SA) do restaurante R2 da Ilha do Mel/PR, em janeiro de 2010.

\begin{tabular}{lcccc}
\hline \multicolumn{1}{c}{ Alimentos } & AM & CT & EC & SA \\
\hline leite utilizado para suco & $1,0 \times 10^{1}$ & 1,0 & $<10$ & $\mathrm{NR}$ \\
peixe cru & $6,5 \times 10^{5}$ & $1,0 \times 10^{4}$ & $<10$ & $1,0 \times 10^{1}$ \\
camarão cru & $1,4 \times 10^{8}$ & $2,0 \times 10^{4}$ & $6,0 \times 10^{2}$ & $1,0 \times 10^{1}$ \\
pastel frito de camarão & $4,0 \times 10^{1}$ & $1,0 \times 10^{1}$ & $<10$ & $1,0 \times 10^{1}$ \\
pastel frito de carne de siri & $1,0 \times 10^{3}$ & $1,0 \times 10^{1}$ & $<10$ & $1,0 \times 10^{1}$ \\
peixe frito & $1,0 \times 10^{1}$ & $1,0 \times 10^{1}$ & $<10$ & $1,0 \times 10^{1}$ \\
camarão frito & $2,0 \times 10^{1}$ & $1,0 \times 10^{1}$ & $<10$ & $1,0 \times 10^{1}$ \\
vinagrete de mexilhão & $1,0 \times 10^{1}$ & $1,0 \times 10^{1}$ & $<10$ & $1,0 \times 10^{1}$ \\
salada & $\mathrm{NR}$ & $1,4 \times 10^{3}$ & $2,0 \times 10^{1}$ & $\mathrm{NR}$ \\
\hline
\end{tabular}

NR: não realizado

Fonte: Elaboração dos autores.

Tabela 7. Contagens de aeróbios mesófilos (AM), coliformes totais (CT), E. coli (EC) e S. aureus (SA) do restaurante R3 da Ilha do Mel/PR, em janeiro de 2010.

\begin{tabular}{lcccc}
\hline \multicolumn{1}{c}{ Alimentos } & AC & CT & EC & SA \\
\hline leite utilizado para suco & $1,5 \times 10^{5}$ & $7,6 \times 10^{4}$ & $<10$ & $\mathrm{NR}$ \\
peixe cru & $1,7 \times 10^{5}$ & $1,1 \times 10^{4}$ & $4,2 \times 10^{3}$ & $3,0 \times 10^{2}$ \\
camarão cru & $7,0 \times 10^{5}$ & $1,2 \times 10^{2}$ & $<10$ & $1,6 \times 10^{2}$ \\
mexilhão congelado & $1,1 \times 10^{8}$ & $7,4 \times 10^{4}$ & $7,0 \times 10^{2}$ & $1,0 \times 10^{1}$ \\
pastel frito de camarão & $1,0 \times 10^{3}$ & $1,0 \times 10^{1}$ & $<10$ & $1,0 \times 10^{1}$ \\
pastel frito de carne de siri & $1,0 \times 10^{1}$ & $1,0 \times 10^{1}$ & $<10$ & $1,0 \times 10^{1}$ \\
peixe frito & $1,0 \times 10^{1}$ & $1,0 \times 10^{1}$ & $<10$ & $1,0 \times 10^{1}$ \\
camarão frito & $2,0 \times 10^{1}$ & $1,0 \times 10^{1}$ & $<10$ & $1,0 \times 10^{1}$ \\
salada & $1,5 \times 10^{5}$ & $7,6 \times 10^{4}$ & $<10$ & $\mathrm{NR}$ \\
\hline
\end{tabular}

NR: não realizado

Fonte: Elaboração dos autores.

Tabela 8. Média das contagens de aeróbios mesófilos (AM), coliformes totais (CT), E. coli (EC), S. aureus (SA) obtidas de alimentos de três restaurantes da Ilha do Mel/PR (UFC/g ou mL), em janeiro de 2010.

\begin{tabular}{lccccc}
\hline \multicolumn{1}{c}{ Alimentos } & n & AM & CT & EC & SA \\
\hline pescado, crustáceo e moluscos in natura & 7 & $2,4 \times 10^{7}$ & $2,1 \times 10^{4}$ & $7,0 \times 10^{2}$ & $7,5 \times 10^{1}$ \\
mexilhão cozidos e congelados & 1 & $1,0 \times 10^{8}$ & $7,5 \times 10^{4}$ & $7,0 \times 10^{2}$ & $<10$ \\
molhos prontos com frutos do mar & 4 & $6,5 \times 10^{6}$ & $1,9 \times 10^{4}$ & $3,5 \times 10^{3}$ & $<10$ \\
queijos & 2 & $1,3 \times 10^{8}$ & $2,1 \times 10^{5}$ & 15 & $<10$ \\
peixe frito & 3 & $4,3 \times 10^{5}$ & 50 & $<10$ & $<10$ \\
pratos prontos a base de frutos do mar & 6 & $1,8 \times 10^{7}$ & $3,9 \times 10^{1}$ & $<10$ & $<10$ \\
presunto & 1 & $1,3 \times 10^{7}$ & $1,2 \times 10^{7}$ & $<10$ & $<10$ \\
leite UHT em uso & 3 & $2,9 \times 10^{5}$ & $1,3 \times 10^{5}$ & $<10$ & $\mathrm{NR}$ \\
saladas consumidos crus & 6 & $\mathrm{NR}$ & $1,3 \times 10^{7}$ & $3,4 \times 10^{4}$ & $\mathrm{NR}$ \\
\hline \multicolumn{1}{c}{ Total } & $\mathbf{3 3}$ & & & \\
\hline
\end{tabular}

$\mathrm{n}$ : número de amostras

NR: não realizado

Fonte: Elaboração dos autores. 
A Resolução RDC n'12, de 02 de janeiro de 2001, estabelece padrões microbiológicos para alimentos (BRASIL, 2001). Para pescado, crustáceos e moluscos congelados ou in natura o padrão para SA é de $10^{3} \mathrm{UFC} / \mathrm{g}$. Para moluscos bivalves, carne de siri e similares, cozidos, resfriados ou congelados a legislação estabelece padrões para coliformes a $45^{\circ} \mathrm{C}$ $\left(5,0 \times 10^{1} \mathrm{UFC} / \mathrm{g}\right)$ e SA $\left(10^{3} \mathrm{UFC} / \mathrm{g}\right)$. Já para pratos prontos a base de pescado o padrão para coliformes a $45^{\circ} \mathrm{C}$ é $2,0 \times 10^{1} \mathrm{UFC} / \mathrm{g}$ e para SA $10^{3} \mathrm{UFC} / \mathrm{g}$. Para pratos a base de verduras e legumes crus o padrão para coliformes a $45^{\circ} \mathrm{C}$ é de $10^{2} \mathrm{UFC} / \mathrm{g}$.

Assim, considerando a legislação em vigor, uma amostra de molho com frutos do mar (restaurante R1) estava em desacordo com os padrões exigidos para coliformes a $45^{\circ} \mathrm{C}$, com 1,4 x $10^{4} \mathrm{UFC} / \mathrm{g}$ de EC. Os demais pratos prontos para servir apresentaram contagens dentro do em acordo com o padrão. Com relação aos pescados, crustáceos e moluscos congelados e in natura, somente a(s) amostra(s) de mexilhão congelado do restaurante R3 apresentou contagens acima do padrão da legislação em relação ao critério microbiológico avaliado, com contagens de $7,0 \times 10^{2} \mathrm{UFC} / \mathrm{g}$ de EC. Embora na legislação não exista padrões para AM e CT, as altas contagens encontradas nos alimentos crus podem ser causa de deterioração e de favorecer a contaminação cruzada entre estes alimentos e os já preparados.

As amostras de queijos eram do tipo mussarela e parmesão, ambas pertencentes ao restaurante R1. A contagem de CT do queijo mussarela foi de 3,7 x $10^{5} \mathrm{UFC} / \mathrm{g}$ e do queijo parmesão, $5,1 \times 10^{4} \mathrm{UFC} / \mathrm{g}$. $\mathrm{A}$ RDC n ${ }^{\circ} 12$ não estabelece padrões para $\mathrm{CT}$ em queijos. Porém, se considerarmos a Portaria $\mathrm{n}^{\circ}$ 364, que estabelece a identidade e as características mínimas de qualidade do queijo mussarela $\left(10^{4}\right.$ UFC/g de CT), do Ministério da Agricultura, Pecuária e Abastecimento (BRASIL, 1997), a amostra estaria com contagens de CT acima do estabelecido.

Duas das três amostras de leite UHT, de caixas abertas, em consumo, conservadas em geladeira, apresentaram altas contagens de AM e CT, indicando que sofreram contaminação durante o uso, provavelmente da própria embalagem que apresentou contagem maior que 3,0 x $10^{8} \mathrm{UFC}$ para AM e $1,5 \times 10^{7}$ UFC para CT.

As saladas, compostas de alface, cenoura ralada e pepino, já consideradas lavadas e limpas, foram os alimentos que demonstraram maior contaminação. A média de CT foi de $1,3 \times 10^{7} \mathrm{UFC} / \mathrm{g}$ e de EC $3,4 \times 10^{4} \mathrm{UFC} / \mathrm{g}$. O componente das saladas que apresentou maior contaminação de EC foi a cenoura ralada $\left(2,0 \times 10^{5} \mathrm{UFC} / \mathrm{g}\right)$, seguida da alface $\left(1,0 \times 10^{3}\right.$ $\mathrm{UFC} / \mathrm{g})$. Quatro $(66,7 \%)$ das seis amostras de salada apresentaram EC, sendo que duas apresentaram contagens acima do estabelecido pela legislação. Resultado semelhante ao encontrado por Paula et al. (2003) que, analisando 30 amostras de salada de alface em restaurantes self-service de Niterói/RJ, encontraram $53,4 \%$ das amostras contaminadas por EC.

Na Tabela 9 estão relacionados os alimentos em desacordo com o padrão microbiológico, segundo a RDC $n^{\circ} 12$ (BRASIL, 2001), por restaurante.

Tabela 9. Alimentos fora do padrão estabelecido na RDC n ${ }^{\circ} 12$ (BRASIL, 2001) para E. coli (EC) de três restaurantes da Ilha do Mel/PR, em janeiro de 2010.

\begin{tabular}{lccc}
\hline \multicolumn{1}{c}{ Alimento } & Restaurante & RDC n $^{\mathbf{0}} \mathbf{1 2}$ (UFC/g) & EC (UFC/g) \\
\hline mexilhão cozido e congelado & $\mathrm{R} 3$ & $5,0 \times 10^{1}$ & $7,0 \times 10^{2}$ \\
molho de camarão & $\mathrm{R} 1$ & $2,0 \times 10^{1}$ & $1,4 \times 10^{4}$ \\
alface & $\mathrm{R} 1$ & $1,0 \times 10^{2}$ & $1,0 \times 10^{3}$ \\
cenoura ralada & $\mathrm{R} 1$ & $1,0 \times 10^{2}$ & $2,0 \times 10^{5}$
\end{tabular}

Fonte: Elaboração dos autores. 
A água utilizada em restaurantes é muito importante para a garantia da qualidade dos alimentos preparados e para a manutenção das condições higiênico-sanitárias das instalações, equipamentos e utensílios. Segundo a Portaria $n^{\circ}$ 1469 de 29 de dezembro de 2000 (BRASIL, 2001), a água para consumo humano deve ter ausência de E. coli em $100 \mathrm{~mL}$ de água. A Tabela 10 mostra que as seis amostras analisadas apresentavam boa qualidade, não sendo encontrada a presença de $E$. coli em nenhuma amostra.

O armazenamento de água das bicas é uma prática comum observada nos três restaurantes. A análise desta água, após 24 e 48 horas de armazenamento, consta na Tabela 11.

Tabela 10. Contagens de coliformes totais (CT) e E. coli (EC) utilizando Petrifilm EC da água das torneiras e das três bicas, utilizadas no preparo dos alimentos nos 3 restaurantes da Ilha do Mel/PR (UFC/mL), em janeiro de 2010.

\begin{tabular}{lccc}
\hline Descrição das amostras & CT & EC \\
\hline água restaurante R1 & 9 & $<1$ \\
água restaurante R2 & $<1$ & $<1$ \\
água restaurante R3 & 1 & $<1$ \\
água bica 1 & 6,4 & $<1$ \\
água bica 2 & 17 & $<1$ \\
água bica 3 & 21 & $<1$ \\
\hline
\end{tabular}

Fonte: Elaboração dos autores.

Tabela 11. Contagem de coliformes totais (CT) da água das três bicas utilizadas para o preparo de alimentos nos três restaurantes da Ilha do Mel/PR (UFC/mL), utilizando placa Petrifilm ${ }^{\mathrm{TM}} \mathrm{HS}$, em janeiro de 2010.

\begin{tabular}{lccc}
\hline \multicolumn{1}{c}{ Amostras } & Bica $\mathbf{1}$ & Bica 2 & Bica 3 \\
\hline 0 hora & 6,4 & 17 & 21 \\
24 horas & 2 & 158 & 320 \\
48 horas & $<2$ & 100 & 440 \\
\hline
\end{tabular}

Fonte: Elaboração dos autores.

A Tabela 11 mostra que a contagem de CT das bicas aumentou com o tempo de armazenamento, com exceção da bica 1. Isto provavelmente ocorre devido à presença de grande quantidade de matéria orgânica nas bicas 2 e 3, que correm à "céu aberto". A bica 1, provavelmente possui menos matéria orgânica pelo fato da sua nascente, e todo seu percurso, ser protegido da interferência do ambiente. Nenhuma amostra apresentou EC.
Os 3 restaurantes estudados apresentavam diferentes características de instalações e práticas por parte dos manipuladores.

O Gráfico 1 mostra a frequência relativa de conformidades dos 3 restaurantes avaliados (R1, R2 e R3). 
Gráfico 1. Frequência relativa de conformidades dos três restaurantes (R1, R2 e R3) da Ilha do Mel/PR, em janeiro de 2010.

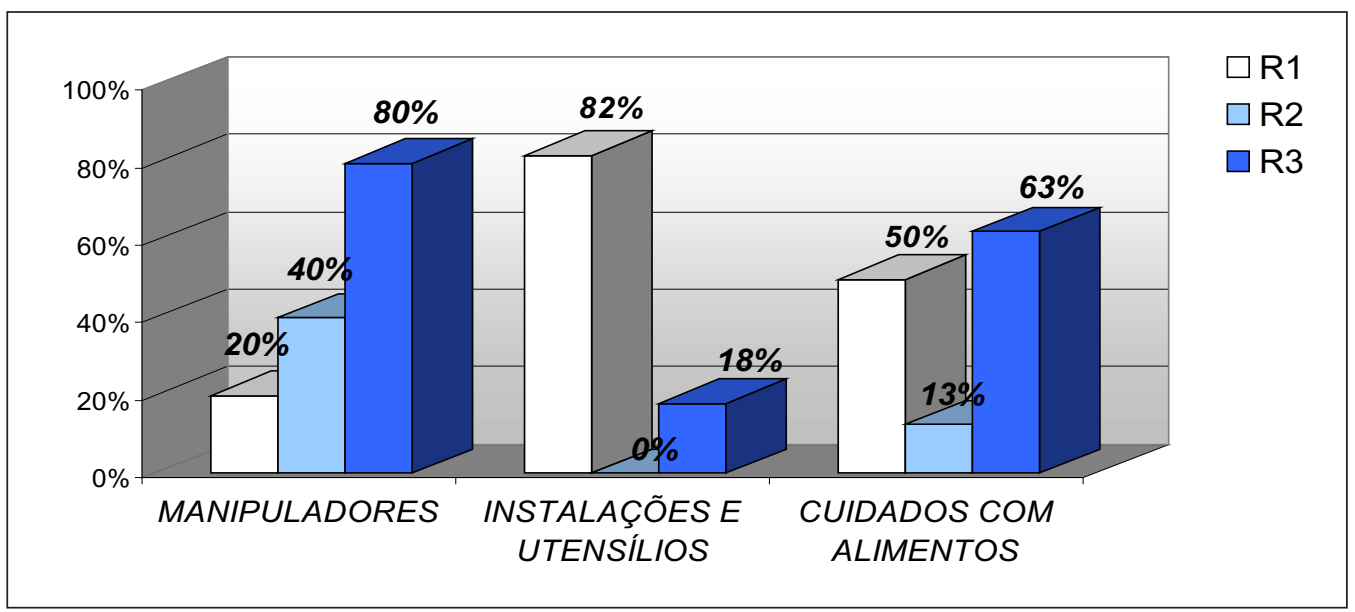

Fonte: Elaboração dos autores.

É importante salientar que o estabelecimento onde os alimentos apresentaram melhores condições higiênicas (Tabela 4) foi o estabelecimento onde os manipuladores foram previamente treinados com cursos de boas práticas de manipulação (R3). $\mathrm{O}$ restaurante que apresentou o pior desempenho (R1) dispunha das melhores instalações (Gráfico 1), porém os funcionários nunca receberam cursos de capacitação e não apresentavam noções de higiene pessoal.

\section{Conclusão}

No presente estudo, esponjas de louça, tábuas de corte, panos de prato, superfície de pias, gelo dos freezers e panos de pia apresentaram altas contagens de micro-organismos, representando importantes fontes de contaminação na cozinha. Assim, requerem maior atenção e frequência de limpeza, sendo necessária a implantação de procedimentos de higiene que impeçam a disseminação da contaminação entre superfícies e alimentos, sobretudo os prontos para o consumo.

Os alimentos, de um modo geral, também apresentaram altas contagens bacterianas, o que indica baixa qualidade da matéria-prima e falha de armazenamento e/ou manipulação. Os alimentos que apresentaram contaminação além do estabelecido pela legislação brasileira foram: mexilhão cozido congelado, molho de camarão, queijo mussarela, alface e cenoura ralada.

As saladas foram os principais responsáveis pela contaminação de tábuas e pias, que podem disseminar a contaminação para outros alimentos e utensílios. Por outro lado, a água utilizada pelos estabelecimentos apresentou boa qualidade.

$\mathrm{O}$ fato de ter as melhores instalações não foi fator determinante para a garantia da qualidade dos alimentos nos restaurantes estudados. A capacitação dos manipuladores em cursos e treinamentos sobre manipulação higiênica garantiu as melhores condições higiênico-sanitárias de instalações, equipamentos, utensílios e alimentos. Os resultados mostram a importância da necessidade de treinamento dos manipuladores e a implantação de Boas Práticas de Manipulação para alcançar a segurança microbiológica dos alimentos. 


\section{Agradecimentos}

Apoio financeiro: Fundação Araucária de Apoio ao Desenvolvimento Científico e Tecnológico do Paraná.

ONG AMARÉ pela disponibilidade do espaço físico para a montagem do laboratório.

\section{Referências}

ANDRADE, N. J.; SILVA, R .M. M.; BRABES, K. C. $\mathrm{S}$. Avaliação das condições microbiológicas em unidade de alimentação e nutrição. Ciência e Agrotecnologia, Lavras, v. 27, n. 3, p. 590-596, maio/jun. 2003.

ASSOCIAÇÃO BRASILEIRA DE NORMAS TÉCNICAS - NBR 10203: preparo da amostra para exame microbiológico. Rio de Janeiro: mar. 1988. 3 p.

BELOTI, V.; FREIRE, R. L.; PACHEMSHY, J. S.; NERO, L. A.; MORAES, L. B.; MATTOS, M. R.; GUSMÃO, V. V.; BARROS, M. A. F. Enumeração de coliformes totais e Escherichia coli em água de abastecimento e de efluentes da Ilha do Mel (PR), utilizando-se placas Petrifilm EC e HS. Revista Higiene Alimentar, São Paulo, v. 16, n. 95, p. 48-52, 2002.

BRASIL. Agência Nacional de Vigilância Sanitária. Resolução RDC $n^{\circ} 12$, de 02 de janeiro de 2001. Regulamento técnico sobre os padrões microbiológicos para alimentos. 2001. Disponível em: < http://e-legis. anvisa.gov.br/leisref/public/showAct.php?id=12546>. Acesso em: 14 mar. 2008.

Ministério da Agricultura, Pecuária e Abastecimento. Portaria $n^{\circ} 364$, de 04 de setembro de 1997. Aprova o regulamento técnico para fixação de identidade e qualidade de queijo Mozzarella (Muzzarella ou Mussarella). 1997. Disponível em:<http://extranet. agricultura.gov.br/sislegis-consulta/consultarLegislacao. do?operacao $=$ visualizar\&id $=1248>$. Acesso em: 19 nov. 2009.

- Ministério da Saúde. Agência Nacional de Vigilância Sanitária. Resolução RDC $n^{\circ} 275$, de 21 de outubro de 2002. Dispõe sobre o regulamento técnico de procedimentos operacionais padronizados aplicados aos estabelecimentos produtores/industrializadores de alimentos e a lista de verificação das boas práticas de fabricação em estabelecimentos produtores/ industrializadores de alimentos. 2002. Disponível em: $\quad<$ http://e-legis. bvs.br/leisref/public/showAct. php?id=8134 $>$. Acesso em: 13 nov. 2007.
Ministério da Saúde. Portaria n. 1469, de 29 de dezembro de 2000. Aprova a norma de qualidade de água para consumo humano. Diário Oficial [da] União, Brasília, 21 de janeiro de 2001.

Ministério da Saúde. Sistema de informações hospitalares do SUS. 2007. Disponível em: <http:// tabnet.datasus.gov.br/tabnet/tabnet.htm>. Acesso em: 20 dez. 2007.

CARRASCO, L.; MENA, K. D.; MOTA, L. C.; ORTIZ, M.; BEHRAVESH, C. B.; BRISTOL, J. R. Occurrence of fecal contamination in household along the US-Mexico border. Letters of Applied Microbiology, Oxford, v. 46, n. 6 , p. 682-687, 2008.

COELHO, A. I. M.; MILAGRES, R. C. R. M.; MARTINS, J. F. L.; AZEREDO, R. M. C.; SANTNA, A. M. C. Contaminação microbiológica de ambientes e de superfícies em restaurantes comerciais. Ciências \& Saúde Coletiva, Rio de Janeiro, v. 15, n. 1, p. 1597-1606, 2010.

COGAN, T. A.; BLOOMFIELD, S. F.; HUMPHREY, T. $\mathrm{J}$. The effectiveness of hygiene procedures for prevention of cross-contamination from chicken carcasses in the domestic kitchen. Letters of Applied Microbiology, Oxford, v. 29, n 5, p. 354-358, 1999.

EISEL, W. G.; LINTON, R. H.; MURIANA, P. M. A survey of microbial levels for incoming raw beef, environmental sources, and ground beef in a red meat processing plant. Food Microbiology, London, v. 14, n. 3, p. 273-282, 1997.

FALCÃO, J. P.; DIAS, A. M. G.; CORREA, E. F.; FALCÃO, D. P. Microbiological quality of ice used to refrigerate foods. Food Microbiology, London, v. 19, n. 4, p. 269-276, 2002.

FRANCO, B. D. G. M. Microbiologia dos alimentos. 2. ed. São Paulo: Atheneu, 2003.

GILL, C. O. Microbiological contamination of meat during slaughter and butchering of cattle, sheep and pigs. In: DAVIES, A.; BOARD, R. (Ed.). Microbiology of meat and poultry. London: Blackie Academic and Professional, 1998. p. 118-157.

JACKSON, V.; BLAIR, I. S.; MCDOWELL, D. A.; KENNEDY, J.; BOLTON, D. J. The incidence of significant foodborne pathogens in domestic refrigerators. Food Control, Vurrey, v. 18, n. 4, p. 346-351, 2007.

JAY, J. M. Indicators of food microbial quality and safety. In: JAY, J. M.; LOESSNER, M. J.; GOLDEN, D. A. (Ed.). Modern food microbiology. 6. ed. Berkely: Springer, chapter 20, 2000. p. 387-409. 
JOSEPHSON, K. L.; RUBINO, J. R.; PEPPER, I. L. Characterization and quantification of bacterial pathogens and indicator organisms in household kitchens with and without the use of a disinfectant cleaner. Journal of Applied Bacteriology, London, v. 83, n. 5, p. 737-750, 1997.

KOCHANSKI, S.; PIEROZAN, M. K.; MOSSI, A. J.; TREICHEL, H.; CANSIAN, R. L.; GHISLENI, C. P.; TONIAZZO, G. Avaliação das condições microbiológicas de uma unidade de alimentação e nutrição. Alimentos $e$ Nutrição, Araraquara, v. 20, n. 4, p. 663-668, 2009.

PAULA, P.; RODRIGUES, P. S. S.; TÓRTORA, J. C. O.; UCHÔA, C. M. A.; FARAGE, S. Contaminação microbiológica e parasitológica em alfaces (Lactuca sativa) de restaurantes self-service, de Niterói, RJ. Revista da Sociedade Brasileira de Medicina Tropical, Uberaba, v. 36, n. 4, p. 535-537, 2003.

RUSIN, P.; OROSZ-COUGHLIN, P.; GERBA, C. Reduction of fecal coliform, coliform and heterotrophic plate count bacteria in the household kitchens and bathroom by disinfection with hypochlorite cleaners. Journal of Applied Microbiology, London, v. 85, n. 6, p. 819-828, 1998.

SVEUM, W. H.; MOBERG, L. J.; RUDE, R.A.; FRANK, J. F. Microbiological monitoring of the food processing environment. In: VANDERZANT, C.; SPLITTSTOESSER, D. F.; SPECK, M. L. Compendium of methods for the microbiological examination of foods. 3. ed. Washington: APHA, 1992. cap. 3, p. 51-74. 